\title{
DETERMINING THE EFFECTS OF SEWAGE SLUDGE AND RHIZOBIUM INOCULATION ON NUTRIENT AND HEAVY METAL CONTENT OF LENTIL (LENS CULINARIS MEDIC.)
}

\author{
ÇıĞ, F. ${ }^{1 *}$-ERMAN, M. ${ }^{1}-$ SÖNMEZ, F. ${ }^{2}$ \\ ${ }^{I}$ Department of Field Crops, Faculty of Agriculture, Siirt University, Siirt, Turkey \\ ${ }^{2}$ Department of Seed Science \& Technology, Faculty of Agriculture and Natural Sciences \\ Bolu Abant İzet Baysal University, Bolu, Turkey \\ *Corresponding author \\ e-mail:fatihcig@hotmail.com
}

(Received $28^{\text {th }}$ Nov 2018; accepted $28^{\text {th }}$ Jan 2019)

\begin{abstract}
This study investigates the effects of increasing doses of sewage sludge with Rhizobium inoculation on lentil (Lens culinaris Medic.) straw and grain macro, micro and heavy metal contents in 2003-2004 and 2004-2005 growing seasons. Experiment was conducted as a randomized complete block design with 3 replications. At the end of the study, it was seen that Rhizobium inoculation affects the N, $\mathrm{Mg}$, and $\mathrm{Pb}$ contents of the lentil straw on by $\mathrm{P}<0.05, \mathrm{P}$ and $\mathrm{Ca}$ contents by $\mathrm{P}<0.01$ in the first year; the $\mathrm{N}$, $\mathrm{Fe}$, and $\mathrm{Zn}$ contents on $\mathrm{P}<0.05$ level, on the $\mathrm{Pb}$ content $\mathrm{P}<0.01$ level in the second year. Lentil grains were affected only on the $\mathrm{K}, \mathrm{Fe}, \mathrm{Pb}$, and $\mathrm{Cd}$ contents by $\mathrm{P}<0.05$. Sewage sludge applications were used to detect the effects on the $\mathrm{N}, \mathrm{Mg}, \mathrm{Fe}, \mathrm{Mn}$ and $\mathrm{Cu}$ contents of the lentil straw by $\mathrm{P}<0.01$, Co content by $\mathrm{P}<0.05$, and $\mathrm{Pb}$ content by $\mathrm{P}<0.01$ in first year; on the $\mathrm{N}, \mathrm{K}, \mathrm{Zn}$ and $\mathrm{Pb}$ contents by $\mathrm{P}<0.01, \mathrm{P}$ and $\mathrm{Mn}$ contents by $\mathrm{P}<0.01$, on the $\mathrm{Mg}, \mathrm{Fe}, \mathrm{Cu}$, and $\mathrm{Co}$ contents by $\mathrm{P}<0.05$ in the second year. Effects received by the lentil grains are as follows: The $\mathrm{N}, \mathrm{K}$, and $\mathrm{Cu}$ contents by $\mathrm{P}<0.01$, on the $\mathrm{Pb}, \mathrm{Fe}, \mathrm{P}$, and $\mathrm{Mg}$ contents by $\mathrm{P}<0.01$, on the $\mathrm{Ca}$ and $\mathrm{Zn}$ contents by $\mathrm{P}<0.05$ in the first year; on the $\mathrm{P}, \mathrm{K}, \mathrm{Ca}, \mathrm{Mg}, \mathrm{Fe}, \mathrm{Mn}, \mathrm{Zn}, \mathrm{Cu}$ and $\mathrm{Co}$ contents by $\mathrm{P}<0.01$, on the $\mathrm{Pb}$ content by $\mathrm{P}<0.05$ in the second year. The effects of inoculation on the lentil straw and grain, regarding the nutrient and heavy metal contents were determined to be insignificant. This result may be a result of weak inoculation application and the heavy metal content of the sewage sludge, as well as the negative effects of Rhizobium inoculation.
\end{abstract}

Keywords: Cadmium, macro nutrients, legume, Rhizobium, municipal waste sludge

\section{Introduction}

One of the preferred methods to remove sewage sludge in industrialized and populous countries is to use sewage sludge in agricultural production under controlled conditions. Particularly, sewage sludge derived industrial waste cause health problems because of the potential toxic substance like heavy metals, phenolics (Mueller et al., 1989; Van Assche and Clijsters, 1990). Moreover, the organic substance of soils is low. In order to achieve steady agricultural production, and taking into account the limited organic fertilizer resources - used for preserving or increasing the organic substance content of soils - scientists have been using sewage sludge.

High or low of organic substance extent of soils have effects on physical, chemical and biological specification directly and indirectly. The organic fertilizer source used includes nutrient elements (stable manure, poultry manure, refuse compost, sewage sludge) and the content of potential toxic elements affect the frequency of application in agricultural production. In addition, the $\mathrm{pH}$ of the soil affects the amount and place of application of the sewage sludge (Logan and Chaney, 1983). 
Generally, it is preferred that sewage sludge is applied to the soil which has $6 \mathrm{pH}$ or more. Because sewage sludge contains elements especially like $\mathrm{Cd}, \mathrm{Zn}$ and $\mathrm{Ni}$. These have high activity on acidic soils. Using sewage sludge in agricultural production improves physical characteristic of the soil and it functions as a source of nutrition elements for plants (Smith, 1996). The important thing here is that we should be careful in the harvest period after sewage sludge applied. Because after sewage sludge is applied, there should be a delay period before harvesting and therefore, sewage sludge applications must be done considering the harvest periods (Lovell et al., 1995).

As sewage sludge includes potential toxic substances, it has serious effects on macro and micro flora of soils (Sterritt and Lester, 1980; Brynhildsen and Rosswall, 1997; Athar and Ahmad, 2002). So, some researchers had investigated and found out what the sewage sludge effects on the soil development and soil microorganism are (Sönmez, 2003; Tüfenkçi et al., 2006a). According to the research, microorganisms had developed some mechanism against the toxic substances, but Rhizobium bacteria (Haferburg and Kothe, 2007), was discovered to be especially vulnerable to them (Chaudri et al., 1993, 2000). Therefore, soil organisms especially Rhizobiums where sewage sludge are applied face some important problems. In the area where sewage sludge is applied, heavy metal loading in different organs of plants has been monitored (Xian, 1989; Nellesen and Fletcher, 1993; Yürük and Bozkurt, 2006). The legumes used in the rehabilitation of contaminated areas with heavy metals (Zribi et al., 2012), and especially the presence of microbial density produced by plants in the rhizosphere and root exudates are very important (Glick, 2004). It has been reported that it has a negative effect on the inoculation of cadmium, copper and zinc Rhizobium in areas where treatment sludge has been applied for many years (Charlton et al., 2016).

In this study, we aimed to determine the effects of Rhizobium budding on the nutrition element of the straw and grain and monitor the changes on the heavy metal content after the application of sewage sludge on the lentil plant.

\section{Materials and Methods}

This study was carried out on the experiment area of Van Yüzüncü Y1l University in Eastern Anatolia in Turkey (between latitudes $35^{\circ} 57^{\prime} 84 \mathrm{~N}$ and longitudes $42^{\circ} 74^{\prime} 61 \mathrm{E}$ at an elevation of $1725 \mathrm{~m}$ ) in 2003-04 and 2004-05 growing seasons using one red-seeded nationally registered lentil cultivar (cv. Sazak-91) with 1000-seed weight of $30 \mathrm{~g}$. Annual amounts of rainfall were $349.7 \mathrm{~mm}$ and $421.2 \mathrm{~mm}$ in 2003-04 and 2004-05, respectively. Average temperatures were $9.9^{\circ} \mathrm{C}$ in $2003-04$ and $9.6^{\circ} \mathrm{C}$ in $2004-05$ (Table 1). The results of the elemental analysis of the treatment area soil and the sewage sludge used in the experiment were given in Table 2.

Seeds were inoculated using peat inoculants which included a mixture of nodule-forming strains of Rhizobium leguminosarum biovar viciae specific to lentil. Peat inoculant was prepared with commercial peat cultures provided by the Soil and Fertilizer Research Institute, Ankara, Turkey, according to the method of Somesagaran and Hoben (1994). Peat inoculants were kept in a refrigerator at $+4{ }^{0} \mathrm{C}$ until they were used. It was separately provided from the Soil and Fertilizer Research Institute in 2003-04 and 2004-05 winter seasons. Content and activity of peat inoculants were checked before the trials in 2003-04 and 2004-05. Peat inoculants was used after cell count was adjusted to $1 \times 10^{8}$ Rhizobium cells $\mathrm{g}^{-1}$ so the content of peat culture was standardized by diluting peat inoculants. The most probable number (MPN) method was used for estimating viable cells of Rhizobium (Somesagaran and Hoben, 1994). 
Table 1. Meteorological data for the growing seasons of 2003-2004, 2004-2005 and longterm averages in Van, Turkey (TSMS, 2006)

\begin{tabular}{|c|c|c|c|c|c|c|c|c|c|}
\hline \multirow{2}{*}{ Months } & \multicolumn{3}{|c|}{ Precipitation $(\mathbf{m m})$} & \multicolumn{3}{|c|}{ Average temperature $\left({ }^{\circ} \mathbf{C}\right)$} & \multicolumn{3}{|c|}{ Relative humidity (\%) } \\
\hline & 2003-04 & 2004-05 & LTA* & 2003-04 & 2004-05 & LTA* & 2003-04 & 2004-05 & LTA* \\
\hline September & 16.4 & - & 13.0 & 17.0 & 18.0 & 17.2 & 64.5 & 48.7 & 44.0 \\
\hline October & 23.6 & 48.1 & 45.2 & 13.0 & 12.0 & 10.6 & 71.0 & 64.1 & 58.0 \\
\hline November & 59.6 & 102.4 & 47.9 & 4.5 & 4.6 & 4.4 & 74.3 & 75.1 & 66.0 \\
\hline December & 14.9 & 41.0 & 37.3 & 0.2 & -3.7 & -0.8 & 76.7 & 73.8 & 69.0 \\
\hline January & 25.0 & 34.4 & 35.4 & -0.9 & -3.3 & -3.6 & 78.8 & 77.1 & 68.0 \\
\hline February & 39.6 & 27.2 & 32.5 & -0.6 & -3.3 & -3.2 & 76.1 & 73.7 & 69.0 \\
\hline March & 69.9 & 59.1 & 45.7 & 3.7 & 2.5 & 0.9 & 72.3 & 70.9 & 68.0 \\
\hline April & 26.9 & 55.9 & 56.6 & 6.9 & 8.9 & 7.4 & 66.4 & 64.1 & 62.0 \\
\hline May & 68.7 & 35.8 & 45.0 & 12.4 & 13.3 & 13.0 & 67.8 & 62.5 & 56.0 \\
\hline June & 3.1 & 13.0 & 18.5 & 18.5 & 18.7 & 18.0 & 57.8 & 55.9 & 50.0 \\
\hline July & 2.0 & 0.3 & 5.2 & 21.4 & 24.1 & 22.2 & 52.7 & 51.3 & 44.0 \\
\hline August & - & 4.0 & 3.4 & 22.2 & 23.4 & 21.8 & 46.5 & 62.1 & 41.0 \\
\hline Total & 349.7 & 421.2 & 385.7 & & & & & & \\
\hline Average & & & & 9.9 & 9.6 & 9.0 & 67 & 64.9 & 57 \\
\hline
\end{tabular}

*LTA = Long-term average (1979-2006)

Four doses of trial sewage sludge (SS0; 0 (control), SS10; 10, SS20; 20 and SS40; 40ton $\mathrm{ha}^{-1}$ ) were applied as inoculated and non-inoculated in parcels with 3 repetitions. Sowing was done by hand with $30 \mathrm{~cm}$ row spacing during late October in both years (20 October 2003 and 25 October 2004). The seeding rate was $140 \mathrm{~kg} \mathrm{ha}^{-1}$ with the largegrained Sazak 91. A basal dose of $140 \mathrm{~kg} \mathrm{ha}^{-1} \mathrm{di}$-ammonium phosphate (DAP) was given to each parcel at the time of sowing. Seeds were inoculated with Rhizobium leguminosarum biovar viciae bacteria at the predetermined rates before sowing in all parcels, except for the uninoculated control (Vincent, 1970). Application of the peat inoculant on the seeds was conducted using water which contains $2 \%$ sugar. The parcel size was $1.5 \times 5 \mathrm{~m}$. The experiment was carried out as rain fed. Parcels were handweeded twice each season. Plants were harvested during late June in both years (22 June 2004 and 27 June 2005).

The levels of nitrogen $(\mathrm{N})$, phosphorus $(\mathrm{P})$, potassium $(\mathrm{K})$, magnesium $(\mathrm{Mg})$, calcium $(\mathrm{Ca})$, iron $(\mathrm{Fe})$, manganese $(\mathrm{Mn})$, zinc $(\mathrm{Zn})$, copper $(\mathrm{Cu})$, cobalt $(\mathrm{Co})$, cadmium $(\mathrm{Cd})$ and lead $(\mathrm{Pb})$ were analyzed in dried and grinded samples that straw and grain extracts were obtained from each repetition to be in two parallel according to the methods reported by Kacar and İnal (2008) (Table 3).

At the end of the experiment, as in Jackson (1958), soil samples were taken from 0-20 $\mathrm{cm}$ depth on each repeating and brought to the laboratory and analyzed. The rest was done as follows: Texture, (Bouyoucous, 1951) soil reaction, (Jackson, 1958); total salt, (Richards, 1954): lime, (Hizalan and Ünal, 1966); organic substance, according to modified Walkley Black Method (Walkley, 1947); nitrogen, according to Kjehldahl Method (Kacar, 1994); available phosphorus, according to sodium bicarbonate method (Olsen et al., 1954); exchangeable potassium, calcium and magnesium, according to Thomas (1982) with $1 \mathrm{~N}$ ammonium acetate; micro elements and heavy metals found in soil samples were retrieved after shaking with 0.05 M DTPA (Diethylene Triamine Penta Acetic acid) adjusted to pH 7.3 (Lindsay and Norvel, 1978). These residuals were specified in Atomic Absorption Spectrometer. The values obtained at the end of the experiment were analyzed with Costat statistics program (Düzgüneş et al., 1987). 
Table 2. The results of the chemical and physical analysis of the testing area soil and the sewage sludge

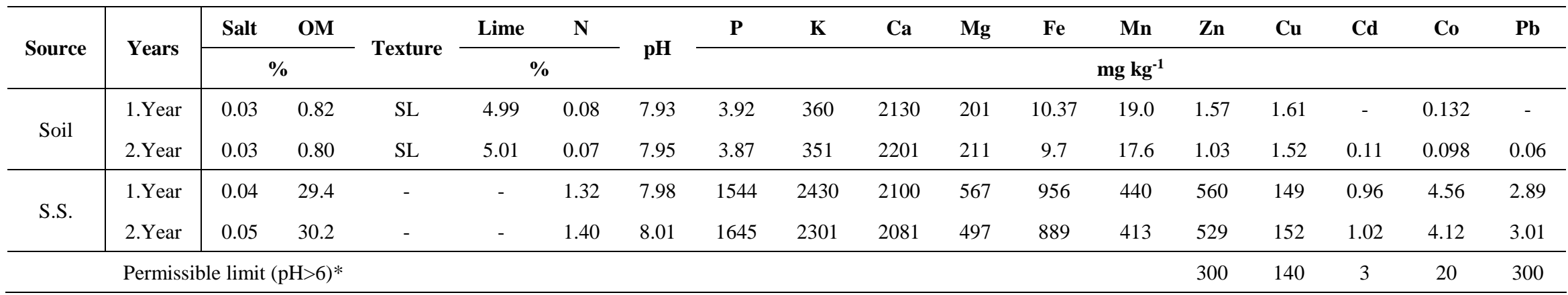

SS: Sewage sludge, OM: Organic matter, *: Anonymous (2003)

Table 3. Results of some chemical and physical analysis of application parcels after testing

\begin{tabular}{|c|c|c|c|c|c|c|c|c|c|c|c|c|c|c|}
\hline \multirow{2}{*}{$\mathbf{R}$} & \multirow{2}{*}{ SS, ton ha-1 } & Salt & OM & Lime & $\mathbf{N}$ & \multirow{2}{*}{ pH } & $\mathbf{P}$ & $\mathbf{K}$ & $\mathbf{C a}$ & $\mathbf{M g}$ & $\mathbf{F e}$ & Mn & $\mathbf{Z n}$ & $\mathbf{C u}$ \\
\hline & & & & & & & \multicolumn{8}{|c|}{$\mathrm{mg} \mathrm{kg}^{-1}$} \\
\hline \multirow{4}{*}{$\mathrm{R}+$} & 0 & $0.026^{*}$ & 0.85 & 6.2 & 0.071 & 7.49 & 3.7 & 499 & 2125 & 208 & 17.2 & 25.5 & 2.9 & 3.1 \\
\hline & 10 & 0.027 & 0.94 & 3.7 & 0.115 & 7.49 & 3.8 & 470 & 2109 & 195 & 18.7 & 22.7 & 2.6 & 1.6 \\
\hline & 20 & 0.023 & 0.97 & 5.2 & 0.119 & 7.47 & 4.3 & 327 & 2160 & 197 & 19.5 & 20.0 & 1.2 & 1.8 \\
\hline & 40 & 0.025 & 1.03 & 4.2 & 0.136 & 7.58 & 6.0 & 411 & 2144 & 184 & 16.4 & 19.7 & 0.4 & 1.4 \\
\hline \multirow{4}{*}{$\mathrm{R}-$} & 0 & 0.021 & 0.82 & 5.0 & 0.080 & 7.73 & 3.9 & 360 & 2130 & 201 & 10.4 & 19.0 & 4.6 & 1.6 \\
\hline & 10 & 0.020 & 0.92 & 3.6 & 0.098 & 7.83 & 4.2 & 305 & 2067 & 161 & 17.6 & 18.0 & 1.8 & 1.4 \\
\hline & 20 & 0.023 & 0.96 & 2.7 & 0.106 & 7.63 & 4.6 & 311 & 2051 & 159 & 16.8 & 20.1 & 1.0 & 1.4 \\
\hline & 40 & 0.018 & 1.04 & 2.7 & 0.132 & 7.73 & 5.3 & 352 & 2040 & 175 & 15.5 & 17.1 & 0.4 & 1.3 \\
\hline
\end{tabular}

R: Rhizobium, R+: Rhizobium inoculate, R-: Rhizobium non-inoculate, SS: Sewage Sludge, OM: Organic Matter, *: values are the average of 3 replications 


\section{Results}

\section{Effects of the application in the content of straw and grain macro elements}

As it can be seen in Table 4, inoculation had a significant effect on both the first and the second year lentil straw $\mathrm{N}(\mathrm{p}<0.01)$ and $\mathrm{Ca}(\mathrm{p}<0.01)$ values, while it had a significant effect on $\mathrm{P}$ and $\mathrm{Mg}(\mathrm{p}<0.01)$ values only on the first year. Its effect on potassium was found to be insignificant in both years. It was seen that while the sewage sludge affected the nitrogen $(\mathrm{p}<0.01)$ on both years, it was discovered that it affected $\mathrm{P}$, $\mathrm{K}$ and $\mathrm{Ca}(\mathrm{p}<0.01)$ only on the second year and $\mathrm{Mg}(\mathrm{p}<0.01)$ only on the first year. It was observed that the interaction only affects nitrogen with a value of $p<0.05$ in both years (Table 4). While the sewage sludge application on the grain nitrogen content had a significant effect on the first year $(\mathrm{p}<0.01)$, it had a significant effect on the $\mathrm{P}, \mathrm{K}, \mathrm{Ca}$, and $\mathrm{Mg}$ elements in both years, respectively as $\mathrm{p}<0.01, \mathrm{p}<0.01, \mathrm{p}<0.05 / \mathrm{p}<0.01$ and $\mathrm{p}<0.01$. Inoculation had a significant in grain nitrogen and phosphorus in both years $(\mathrm{p}<0.01$ and $\mathrm{p}<0.05)$, in potassium and calcium $(\mathrm{p}<0.01$ and $\mathrm{p}<0.05)$, it had a significant effect only in the first year. It was detected that the interaction affected the $\mathrm{K}$ and the $\mathrm{Mg}$ content of the grain macro nutrients on the second year with a level of $\mathrm{p}<0.05$ (Table 5).

Table 4. Effects of Rhizobium and sewage sludge on macro element contents of lentil straw

\begin{tabular}{|c|c|c|c|c|c|c|c|c|c|c|}
\hline \multirow[t]{2}{*}{ Treatments } & \multicolumn{2}{|c|}{$\begin{array}{c}\text { Nitrogen } \\
(\%)\end{array}$} & \multicolumn{2}{|c|}{$\begin{array}{c}\text { Phosphorus } \\
\left(\mathrm{mg} \mathrm{kg}^{-1}\right)\end{array}$} & \multicolumn{2}{|c|}{$\begin{array}{c}\text { Potassium } \\
(\%)\end{array}$} & \multicolumn{2}{|c|}{$\begin{array}{c}\text { Calcium } \\
(\%)\end{array}$} & \multicolumn{2}{|c|}{$\begin{array}{c}\text { Magnessium } \\
(\%)\end{array}$} \\
\hline & 2003-04 & 2004-05 & 2003-04 & 2004-05 & 2003-04 & 2004-05 & 2003-04 & 2004-05 & 2003-04 & 2004-05 \\
\hline \multicolumn{11}{|c|}{ Sewage Sludge (ton ha' $\left.{ }^{-1}\right)(\mathrm{SS})$} \\
\hline SS0 & $1.189 \mathrm{c} * *$ & $1.533 \mathrm{c} * *$ & $1315 b^{n s}$ & $1300 b^{* *}$ & $2.224 b^{n s}$ & $2.127 \mathrm{~d}^{* *}$ & $3.95 b^{n s}$ & $4.60 \mathrm{~b}^{* *}$ & $2.446 \mathrm{c}^{* *}$ & $2.522 b^{*}$ \\
\hline SS10 & $1.290 \mathrm{~b}$ & $1.568 \mathrm{c}$ & $1420 \mathrm{ab}$ & $1417 \mathrm{~b}$ & $2.419 \mathrm{ab}$ & $2.427 \mathrm{c}$ & $4.18 \mathrm{ab}$ & $4.92 \mathrm{~b}$ & $3.507 \mathrm{bc}$ & $2.567 \mathrm{ab}$ \\
\hline SS20 & $1.270 \mathrm{bc}$ & $1.651 \mathrm{~b}$ & $1452 \mathrm{ab}$ & $1762 \mathrm{a}$ & $2.530 \mathrm{ab}$ & $2.799 \mathrm{~b}$ & $4.30 \mathrm{ab}$ & $5.32 \mathrm{a}$ & $3.538 \mathrm{ab}$ & $2.687 \mathrm{ab}$ \\
\hline SS40 & $1.402 \mathrm{a}$ & $1.728 \mathrm{a}$ & $1578 \mathrm{a}$ & $1907 \mathrm{a}$ & $2.597 \mathrm{a}$ & $2.931 \mathrm{a}$ & $4.48 \mathrm{a}$ & $5.48 \mathrm{a}$ & $3.578 \mathrm{a}$ & $2.598 \mathrm{a}$ \\
\hline \multicolumn{11}{|c|}{ Rhizobium (R) } \\
\hline $\mathrm{R}(+)$ & $1.412 \mathrm{a}^{*}$ & $1.693 \mathrm{a}^{*}$ & $1701 \mathrm{a}^{* *}$ & $1610^{\mathrm{ns}}$ & $2.537^{\mathrm{ns}}$ & $2.594^{\mathrm{ns}}$ & $4.443 \mathrm{a}^{* *}$ & $5.32^{\mathrm{ns}}$ & $0.551 \mathrm{a}^{*}$ & $2.568^{\mathrm{ns}}$ \\
\hline $\mathrm{R}(-)$ & $1.164 \mathrm{~b}$ & $1.547 \mathrm{~b}$ & $1183 \mathrm{~b}$ & 1580 & 2.347 & 2.548 & $4.018 \mathrm{~b}$ & 4.79 & $0.484 \mathrm{~b}$ & 2.559 \\
\hline \multicolumn{11}{|c|}{ Interactions (RxSS) } \\
\hline $\mathrm{R}(-) \mathrm{xSS} 0$ & $1.072 \mathrm{~d} *$ & $0.433 \mathrm{~d} * *$ & $1110 \mathrm{~ns}$ & $1291 \mathrm{~ns}$ & $2.182 \mathrm{~ns}$ & $2.089 \mathrm{~ns}$ & $3.606 \mathrm{~ns}$ & $4.503 \mathrm{~ns}$ & $2.410 \mathrm{~ns}$ & 2.515 \\
\hline $\mathrm{R}(-) \mathrm{xSS} 10$ & $1.199 \mathrm{~cd}$ & $0.455 \mathrm{~d}$ & 1168 & 1402 & 2.343 & 2.362 & 3.938 & 4.750 & 2.475 & 2.551 \\
\hline $\mathrm{R}(-) \mathrm{xSS} 20$ & $1.167 \mathrm{~cd}$ & $0.599 \mathrm{c}$ & 1205 & 1833 & 2.392 & 2.835 & 4.134 & 4.935 & 2.512 & 2.610 \\
\hline $\mathrm{R}(-) \mathrm{xSS} 40$ & $1.185 \mathrm{~cd}$ & $0.703 \mathrm{ab}$ & 1246 & 1794 & 2.473 & 2.906 & 4.393 & 5.008 & 2.540 & 2.562 \\
\hline $\mathrm{R}(+) \mathrm{xSS} 0$ & $1.307 \mathrm{bc}$ & $0.633 \mathrm{bc}$ & 1520 & 1311 & 2.266 & 2.164 & 4.297 & 4.697 & 2.481 & 2.530 \\
\hline $\mathrm{R}(+) \mathrm{xSS} 10$ & $1.349 \mathrm{~b}$ & $0.682 \mathrm{ab}$ & 1673 & 1417 & 2.495 & 2.492 & 4.426 & 5.094 & 2.540 & 2.582 \\
\hline $\mathrm{R}(+) \mathrm{xSS} 20$ & $1.372 \mathrm{~b}$ & $0.703 \mathrm{ab}$ & 1700 & 1694 & 2.668 & 2.763 & 4.474 & 5.703 & 2.565 & 2.587 \\
\hline $\mathrm{R}(+) \mathrm{xSS} 40$ & $1.619 \mathrm{a}$ & $0.752 \mathrm{a}$ & 1910 & 2023 & 2.721 & 2.957 & 4.575 & 5.955 & 2.616 & 2.575 \\
\hline
\end{tabular}

ns: not significant; *: Significant at $\mathrm{P}<0.05$ level, **: Significant at $\mathrm{P}<0.01$ level, ${ }^{*}$ : Values followed by the different letters are significantly different, SS0: 0 ton ha- ${ }^{-1}$ SS10: 10 ton ha ${ }^{-1}$, SS20: 20 ton ha ${ }^{-1}$, SS40: 40 ton $\mathrm{ha}^{-1}, \mathrm{R}(-)$ : Rhizobium non-inoculation, $\mathrm{R}(+)$ : Rhizobium inoculation

When the change in the content of straw macro element of lentil at sewage sludge application was investigated, it was seen that the contents of $\mathrm{N}, \mathrm{P}, \mathrm{K}, \mathrm{Ca}$ and $\mathrm{Mg}$ increased considerably in both years according to control. The highest $\mathrm{N}, \mathrm{P}, \mathrm{K}, \mathrm{Ca}$ and $\mathrm{Mg}$ values were reached respectively as $1.402 \%, 1578 \mathrm{mg} \mathrm{kg}^{-1}, 2.597 \%, 4.48 \%$ and $3.578 \%$ at the application of 40 -ton ha $^{-1}$ of sewage sludge in the first year (Table 4 , Figure 1). 
Table 5. Effects of Rhizobium and sewage sludge on macro element contents of lentil grain

\begin{tabular}{|c|c|c|c|c|c|c|c|c|c|c|}
\hline \multirow[t]{2}{*}{ Treatments } & \multicolumn{2}{|c|}{$\begin{array}{c}\text { Nitrogen } \\
(\%)\end{array}$} & \multicolumn{2}{|c|}{$\begin{array}{c}\text { Phosphorus } \\
\left(\mathrm{mg} \mathrm{kg}^{-1}\right)\end{array}$} & \multicolumn{2}{|c|}{$\begin{array}{c}\text { Potassium } \\
(\%)\end{array}$} & \multicolumn{2}{|c|}{$\begin{array}{c}\text { Calcium } \\
(\%)\end{array}$} & \multicolumn{2}{|c|}{$\begin{array}{c}\text { Magnessium } \\
(\%)\end{array}$} \\
\hline & 2003-04 & 2004-05 & 2003-04 & 2004-05 & 2003-04 & 2004-05 & 2003-04 & 2004-05 & 2003-04 & 2004-05 \\
\hline \multicolumn{11}{|c|}{ Sewage Sludge (ton ha-1) (SS) } \\
\hline \begin{tabular}{l|l} 
SS0 & 2
\end{tabular} & $4.339 \mathrm{c} * *$ & $3.681 b^{n s}$ & $5139 \mathrm{~b}^{* *}$ & $* 5328 \mathrm{c} * *$ & $1.072 \mathrm{c}^{* *}$ & $1.277 \mathrm{~d}^{* *}$ & $0.934 \mathrm{~b}^{* *}$ & $1.135 \mathrm{c}^{* *}$ & $0.145 \mathrm{c}^{* *}$ & $0.126 \mathrm{~b}^{* *}$ \\
\hline SS10 & $4.453 \mathrm{bc}$ & $3.840 \mathrm{ab}$ & $5689 \mathrm{a}$ & $5553 \mathrm{~b}$ & $1.133 \mathrm{c}$ & $1.419 \mathrm{c}$ & $1.173 \mathrm{ab}$ & $1.450 \mathrm{~b}$ & $0.188 \mathrm{~b}$ & $0.135 \mathrm{~b}$ \\
\hline SS20 & $4.481 \mathrm{~b}$ & $3.960 \mathrm{ab}$ & 5866 a & $5612 \mathrm{~b}$ & $1.291 \mathrm{~b}$ & $1.611 \mathrm{~b}$ & $1.287 \mathrm{a}$ & $1.510 \mathrm{ab}$ & $0.201 \mathrm{~b}$ & $0.136 \mathrm{~b}$ \\
\hline SS40 & $4.629 \mathrm{a}$ & $4.170 \mathrm{a}$ & 5996 a & 5833 a & $1.463 \mathrm{a}$ & $1.846 \mathrm{a}$ & $1.416 \mathrm{a}$ & $1.589 \mathrm{a}$ & $0.254 \mathrm{a}$ & $0.157 \mathrm{a}$ \\
\hline \multicolumn{11}{|c|}{ Rhizobium (R) } \\
\hline $\begin{array}{l}\mathrm{R}(+) \\
\mathrm{R}(-)\end{array}$ & $\begin{array}{c}4.541 \mathrm{~ns} \\
4.411\end{array}$ & $\begin{array}{c}4.057 \mathrm{~ns} \\
3.768\end{array}$ & $\begin{array}{c}5844 \mathrm{~ns} \\
5501\end{array}$ & $\begin{array}{c}5638 \mathrm{~ns} \\
5532\end{array}$ & $\begin{array}{l}1.300 \mathrm{a}^{*} \\
1.179 \mathrm{~b}\end{array}$ & $\begin{array}{c}1.519 \mathrm{~ns} \\
1.558\end{array}$ & $\begin{array}{c}1.311 \mathrm{~ns} \\
1.093\end{array}$ & $\begin{array}{c}1.459 \mathrm{~ns} \\
1.503\end{array}$ & $\begin{array}{c}0.205 \mathrm{~ns} \\
0.189\end{array}$ & $\begin{array}{c}0.140 \mathrm{~ns} \\
0.138\end{array}$ \\
\hline \multicolumn{11}{|c|}{ Interactions (RxSS) } \\
\hline $\mathrm{R}(-) \mathrm{xSS} 0$ & $4.246 \mathrm{~ns}$ & $3.607 \mathrm{~ns}$ & $4880 \mathrm{~ns}$ & $4208 \mathrm{~ns}$ & $1.020 \mathrm{~ns}$ & $1.228 \mathrm{~b}^{*}$ & $0.0797 \mathrm{~ns}^{\mathrm{s}} \mathrm{C}$ & $0.1363 \mathrm{~ns}$ & $0.132 \mathrm{~ns}$ & $0.126 \mathrm{~ns}$ \\
\hline $\mathrm{R}(-) \mathrm{xSS} 10$ & 4.346 & 3.724 & 5699 & 4506 & 1.078 & $1.457 \mathrm{~b}$ & 0.0988 & 0.1469 & 0.185 & 0.141 \\
\hline $\mathrm{R}(-) \times S S 20$ & 4.411 & 3.862 & 5704 & 4561 & 1.298 & $2.708 \mathrm{a}$ & 0.1239 & 0.1544 & 0.187 & 0.143 \\
\hline $\mathrm{R}(-) \mathrm{xSS} 40$ & 4.638 & 3.879 & 5722 & 4855 & 1.320 & $1.840 \mathrm{ab}$ & 0.1347 & 0.1634 & 0.251 & 0.149 \\
\hline $\mathrm{R}(+) \times S S 0$ & 4.431 & 3.753 & 5398 & 4448 & 1.124 & $1.327 \mathrm{~b}$ & 0.1070 & 0.1386 & 0.158 & 0.127 \\
\hline $\mathrm{R}(+) \mathrm{xSS} 10$ & 4.560 & 3.956 & 5680 & 4601 & 1.188 & $1.382 \mathrm{~b}$ & 0.1358 & 0.1431 & 0.191 & 0.129 \\
\hline $\mathrm{R}(+) \mathrm{xSS} 20$ & 4.551 & 4.059 & 6027 & 4663 & 1.283 & $1.515 \mathrm{~b}$ & 0.1334 & 0.1476 & 0.216 & 0.129 \\
\hline $\mathrm{R}(+) \mathrm{xSS} 40$ & 4.620 & 4.461 & 6269 & 4840 & 1.605 & $1.852 \mathrm{ab}$ & 0.1484 & 0.1545 & 0.257 & 0.165 \\
\hline
\end{tabular}

ns: not significant; *: Significant at $\mathrm{P}<0.05$ level, **: Significant at $\mathrm{P}<0.01$ level, *: Values followed by the different letters are significantly different, SS0: 0 ton ha ${ }^{-1}$, SS10: 10 ton ha ${ }^{-1}$, SS20: 20 ton ha ${ }^{-1}$, SS40: 40 ton $\mathrm{ha}^{-1}, \mathrm{R}(-)$ : Rhizobium non-inoculation, $\mathrm{R}(+)$ : Rhizobium inoculation

Same results were reached also in the second year, but only the content of $\mathrm{Mg}$ value was reached as $2.687 \%$ at application of 20 -ton $\mathrm{ha}^{-1}$ of the sewage sludge. At the application of 40-ton ha ${ }^{-1}$ of sewage sludge, the highest values of $\mathrm{N}, \mathrm{P}, \mathrm{K}, \mathrm{Ca}$ and $\mathrm{Mg}$ were determined as $1.728 \%, 1907 \mathrm{mg} \mathrm{kg}^{-1}, 2.931 \%, 5.48 \%$ and $2.569 \%$, respectively. The lowest value of both years was determined in control parcels (Table 4, Figure 1).

After statistical analyses, straw macro element of lentil in inoculated parcels increased in both years as compared to non-inoculated parcels. It was seen that $\mathrm{N}$ content in this increase was significant in both years; $\mathrm{P}, \mathrm{Ca}$ and $\mathrm{Mg}$ are significant only in the first year. Increase in potassium content was not significant (Table 4). Inoculation resulted in significant increases in the nitrogen, phosphorus, calcium and magnesium content of lentils. A significant increase was detected for $\mathrm{N}$ in both years; for $\mathrm{P}, \mathrm{Ca}$ and $\mathrm{Mg}$ it was only detected in the first year. It was seen that the decrease and increase in potassium content was statistically insignificant (Table 4, Figure 1).

At the application of 40 -ton ha $^{-1}$ of sewage sludge, the highest value was reached in both years. The lowest value in both years was determined in control parcels. The highest value on grain of $\mathrm{N}, \mathrm{P}, \mathrm{K}, \mathrm{Ca}$ and $\mathrm{Mg}$ elements were respectively detected as $4.629 \%, 0.599 \%, 1.463 \%, 0.142 \%$ and $0.254 \%$ in first year, as $4.170 \%, 0.583 \%$, $1.846 \%, 0.159 \%$ and $0.157 \%$, respectively in second year (Table 5, Figure 1).

\section{The effect of application to the straw and grain micro element content of lentil}

The results of variance analysis and the results of the averages of the effect of straw and grain micro element content of lentil and Rhizobium applications are given in Table 5, 6 and Figure 2. 


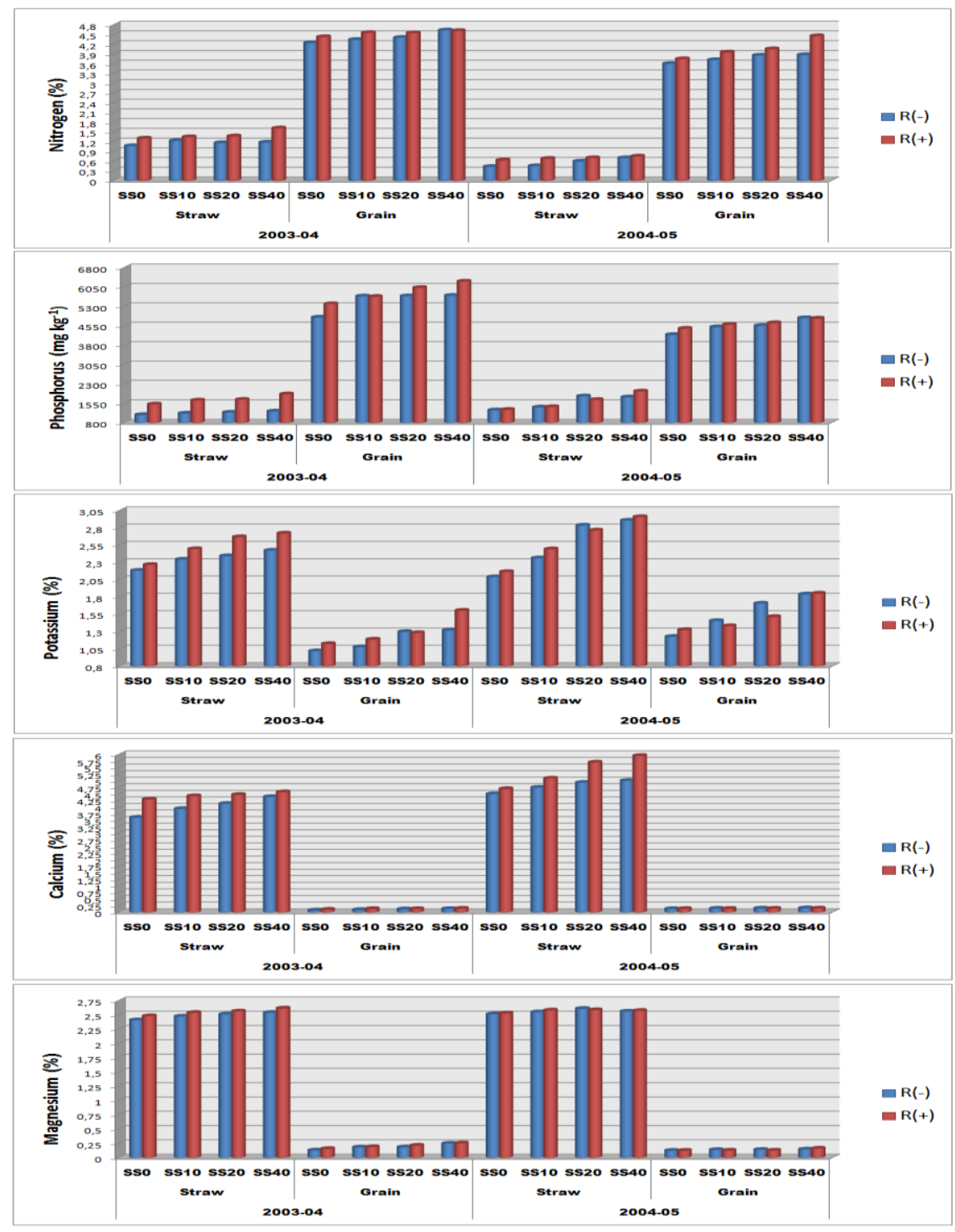

Figure 1. Effects of applications on lentil straw and grain macro element contents

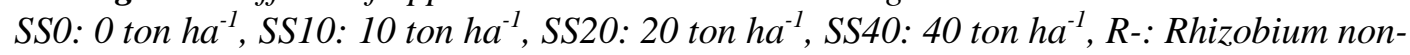
inoculation, $R+$ : Rhizobium non-inoculation

The application of sewage sludge affected the content of straw iron value of lentil by $\mathrm{P}<0.01$ in first year, by $\mathrm{P}<0.05$ in the second year. It affected the manganese content by $\mathrm{P}<0.01$ in both years; zinc content by $\mathrm{P}<0.01$ in the second year while it was insignificant in the first year. Copper content was affected by $\mathrm{P}<0.01$ in the first year, by $\mathrm{P}<0.05$ in the second year. Inoculation affected the content of manganese and copper in both years, while it affected the content of iron and zinc by $\mathrm{P}<0.05$ in the second year. It was seen that its effect on iron and zinc application in the first year was insignificant (Table 6).

Inoculation effect on the grain micro element content was significant for $\mathrm{Fe}$ and $\mathrm{Zn}$ $(\mathrm{p}<0.01)$ in both years and for $\mathrm{Mn}$ in the second year $(\mathrm{p}<0.01)$. The sewage sludge application was significant for $\mathrm{Fe}, \mathrm{Zn}$ and $\mathrm{Cu}(\mathrm{p}<0.01 / \mathrm{p}<0.05)$ in both years and for Mn $(\mathrm{p}<0.01)$ in the second year. The effect of the interaction was detected as significant in the second year only in $\mathrm{Mn}(\mathrm{p}<0.01)$ (Table 7). 
Table 6. Effects of Rhizobium and sewage sludge on micro element contents of lentil straw

\begin{tabular}{|c|c|c|c|c|c|c|c|c|}
\hline \multirow{2}{*}{ Treatments } & \multicolumn{2}{|c|}{ Iron $\left(\mathrm{mg} \mathrm{kg}^{-1}\right)$} & \multicolumn{2}{|c|}{ Manganese (mg kg-1) } & \multicolumn{2}{|c|}{ Zinc (mg kg-1) } & \multicolumn{2}{|c|}{ Copper (mg kg-1) } \\
\hline & 2003-04 & 2004-05 & 2003-04 & 2004-05 & 2003-04 & 2004-05 & 2003-04 & 2004-05 \\
\hline \multicolumn{9}{|c|}{ Sewage Sludge (ton ha' $\left.{ }^{-1}\right)(\mathrm{SS})$} \\
\hline SS0 & $50.6 \mathrm{c}^{* *}$ & $28.9 b^{*}$ & $54.8 \mathrm{~b} * *$ & $44.8 \mathrm{~b}^{* *}$ & $6.07 \mathrm{a} \mathrm{ns}$ & $6.29 \mathrm{c} * *$ & $7.12 b^{* *}$ & $7.84 b^{*}$ \\
\hline SS10 & $57.6 \mathrm{bc}$ & $34.4 \mathrm{ab}$ & $61.5 \mathrm{a}$ & $46.0 \mathrm{~b}$ & $6.42 \mathrm{a}$ & $7.42 \mathrm{~b}$ & $9.55 \mathrm{a}$ & $9.23 \mathrm{ab}$ \\
\hline SS20 & $68.3 \mathrm{ab}$ & $36.9 \mathrm{ab}$ & $64.2 \mathrm{a}$ & $46.7 \mathrm{~b}$ & $6.53 \mathrm{a}$ & $8.03 \mathrm{ab}$ & $10.48 \mathrm{a}$ & $9.39 \mathrm{a}$ \\
\hline SS40 & $72.9 \mathrm{a}$ & $42.9 \mathrm{a}$ & $67.7 \mathrm{a}$ & $56.3 \mathrm{a}$ & $6.57 \mathrm{a}$ & $8.66 \mathrm{a}$ & $11.07 \mathrm{a}$ & $10.12 \mathrm{a}$ \\
\hline \multicolumn{9}{|l|}{ Rhizobium (R) } \\
\hline $\mathrm{R}(+)$ & $63.5 \mathrm{~ns}$ & $39.7 a^{*}$ & $65.2 \mathrm{~ns}$ & $47.4 \mathrm{~ns}$ & $5.79 \mathrm{~ns}$ & $7.81 \mathrm{~ns}$ & $9.54 \mathrm{~ns}$ & $9.15 \mathrm{~ns}$ \\
\hline $\mathrm{R}(-)$ & 61.2 & $31.9 \mathrm{~b}$ & 58.9 & 49.5 & 6.86 & 7.39 & 9.57 & 9.15 \\
\hline \multicolumn{9}{|c|}{ Interactions (RxSS) } \\
\hline $\mathrm{R}(-) \mathrm{xSS} 0$ & $49.5 \mathrm{~ns}$ & $24.5 \mathrm{~ns}$ & $52.5 \mathrm{~ns}$ & $46.2 * *$ & $6.33 \mathrm{~ns}$ & $6.26 \mathrm{~ns}$ & $7.28 \mathrm{~ns}$ & $8.01 \mathrm{~ns}$ \\
\hline $\mathrm{R}(-) \mathrm{xSS} 10$ & 54.2 & 31.9 & 56.4 & 47.7 & 6.56 & 6.97 & 10.13 & 9.09 \\
\hline $\mathrm{R}(-) \mathrm{xSS} 20$ & 68.8 & 31.8 & 50.4 & 47.9 & 7.37 & 7.77 & 9.90 & 9.32 \\
\hline $\mathrm{R}(-) \mathrm{xSS} 40$ & 72.3 & 39.5 & 66.3 & 56.2 & 7.18 & 8.55 & 10.97 & 10.15 \\
\hline $\mathrm{R}(+) \mathrm{xSS} 0$ & 51.8 & 33.4 & 57.2 & 43.2 & 5.79 & 6.31 & 6.96 & 7.67 \\
\hline $\mathrm{R}(+) \times S S 10$ & 60.8 & 36.9 & 66.6 & 44.4 & 6.3 & 7.87 & 8.97 & 9.37 \\
\hline $\mathrm{R}(+) \mathrm{xSS} 20$ & 67.8 & 42.0 & 68.0 & 45.5 & 5.8 & 8.29 & 11.06 & 9.46 \\
\hline $\mathrm{R}(+) \mathrm{xSS} 40$ & 73.2 & 46.4 & 68.9 & 56.4 & 5.38 & 8.76 & 11.17 & 10.09 \\
\hline
\end{tabular}

ns: not significant; *: Significant at $\mathrm{P}<0.05$ level, **: Significant at $\mathrm{P}<0.01$ level, ${ }^{*}$ : Values followed by the different letters are significantly different, SS0: 0 ton ha ${ }^{-1}$, SS10: 10 ton ha ${ }^{-1}$, SS20: 20 ton ha ${ }^{-1}$, SS40: 40 ton $\mathrm{ha}^{-1}, \mathrm{R}(-)$ : Rhizobium non-inoculation, $\mathrm{R}(+)$ : Rhizobium inoculation

Table 7. Effects of Rhizobium and sewage sludge on micro element contents of lentil grain

\begin{tabular}{|c|c|c|c|c|c|c|c|c|}
\hline \multirow{2}{*}{ Treatments } & \multicolumn{2}{|c|}{ Iron $\left(\mathbf{m g ~ k g}{ }^{-1}\right)$} & \multicolumn{2}{|c|}{ Manganese (mg kg-1) } & \multicolumn{2}{|c|}{ Zinc (mg kg-1) } & \multicolumn{2}{|c|}{ Copper (mg kg-1) } \\
\hline & 2003-04 & 2004-05 & 2003-04 & 2004-05 & 2003-04 & 2004-05 & 2003-04 & 2004-05 \\
\hline \multicolumn{9}{|c|}{ Sewage Sludge (ton ha-1) (SS) } \\
\hline SS0 & $48.1 \mathrm{c} * *$ & $67.9 \mathrm{~d}^{* *}$ & $10.7 \mathrm{~ns}$ & $11.0 \mathrm{c} * *$ & $16.37 \mathrm{~b}^{*}$ & $11.85 \mathrm{c}^{* *}$ & $10.18 \mathrm{c}^{* *}$ & $7.85 \mathrm{c}^{* *}$ \\
\hline SS10 & $54.2 \mathrm{bc}$ & $95.2 \mathrm{c}$ & 11.3 & $14.3 \mathrm{~b}$ & $17.39 \mathrm{ab}$ & $13.65 \mathrm{~b}$ & $10.39 \mathrm{bc}$ & $8.42 \mathrm{~b}$ \\
\hline SS20 & $58.8 \mathrm{~b}$ & $123.3 \mathrm{~b}$ & 11.2 & $14.8 \mathrm{~b}$ & $17.81 \mathrm{ab}$ & $14.49 \mathrm{~b}$ & $11.08 \mathrm{ab}$ & $9.09 \mathrm{a}$ \\
\hline SS40 & $81.8 \mathrm{a}$ & $166.2 \mathrm{a}$ & 10.0 & $16.7 \mathrm{a}$ & $18.98 \mathrm{a}$ & $16.57 \mathrm{a}$ & $11.70 \mathrm{a}$ & $9.16 \mathrm{a}$ \\
\hline \multicolumn{9}{|c|}{ Rhizobium (R) } \\
\hline $\mathrm{R}(+)$ & $66.1 \mathrm{a}^{* *}$ & $121.7 \mathrm{~ns}$ & $10.8 \mathrm{~ns}$ & $13.5 \mathrm{~ns}$ & $18.41 \mathrm{~ns}$ & $13.18 \mathrm{~ns}$ & $10.87 \mathrm{~ns}$ & $8.56 \mathrm{~ns}$ \\
\hline $\mathrm{R}(-)$ & $55.3 \mathrm{~b}$ & 104.6 & 10.8 & 14.9 & 16.87 & 15.10 & 10.81 & 8.69 \\
\hline \multicolumn{9}{|c|}{ Interactions (RxSS) } \\
\hline $\mathrm{R}(-) \mathrm{xSS} 0$ & $42.8 \mathrm{~ns}$ & $63.8 \mathrm{~ns}$ & $10.7 \mathrm{~ns}$ & $10.7 \mathrm{c}^{* *}$ & $15.17 \mathrm{~ns}$ & $12.29 \mathrm{~ns}$ & $9.83 \mathrm{~ns}$ & $7.61 \mathrm{~ns}$ \\
\hline $\mathrm{R}(-) \mathrm{xSS} 10$ & 46.7 & 86.1 & 12.2 & $14.2 \mathrm{~b}$ & 16.74 & 14.58 & 11.08 & 8.37 \\
\hline $\mathrm{R}(-) \mathrm{xSS} 20$ & 53.6 & 107.9 & 9.8 & $15.5 \mathrm{~b}$ & 17.35 & 15.17 & 10.35 & 9.33 \\
\hline $\mathrm{R}(-) \mathrm{xSS} 40$ & 78.3 & 160.5 & 6.5 & $19.2 \mathrm{a}$ & 18.19 & 18.37 & 11.98 & 9.46 \\
\hline $\mathrm{R}(+) \mathrm{XSS} 0$ & 53.5 & 72.0 & 10.6 & $11.4 \mathrm{c}$ & 17.57 & 11.40 & 10.54 & 8.08 \\
\hline $\mathrm{R}(+) \mathrm{xSS} 10$ & 61.7 & 104.2 & 10.4 & $14.1 \mathrm{~b}$ & 18.03 & 12.73 & 11.08 & 8.47 \\
\hline $\mathrm{R}(+) \mathrm{xSS} 20$ & 64.0 & 138.6 & 11.7 & $14.3 \mathrm{~b}$ & 18.28 & 13.81 & 10.42 & 8.85 \\
\hline $\mathrm{R}(+) \mathrm{xSS} 40$ & 85.3 & 171.8 & 10.6 & $14.3 \mathrm{~b}$ & 19.76 & 14.76 & 11042 & 8.85 \\
\hline
\end{tabular}

ns: not significant; *: Significant at $\mathrm{P}<0.05$ level, $* *$ : Significant at $\mathrm{P}<0.01$ level, ${ }^{*}$ : Values followed by the different letters are significantly different, SS0: 0 ton ha ${ }^{-1}$, SS10: 10 ton ha ${ }^{-1}$, SS20: 20 ton ha ${ }^{-1}$, SS40: 40 ton $\mathrm{ha}^{-1}, \mathrm{R}(-)$ : Rhizobium non-inoculation, $\mathrm{R}(+)$ : Rhizobium inoculation 


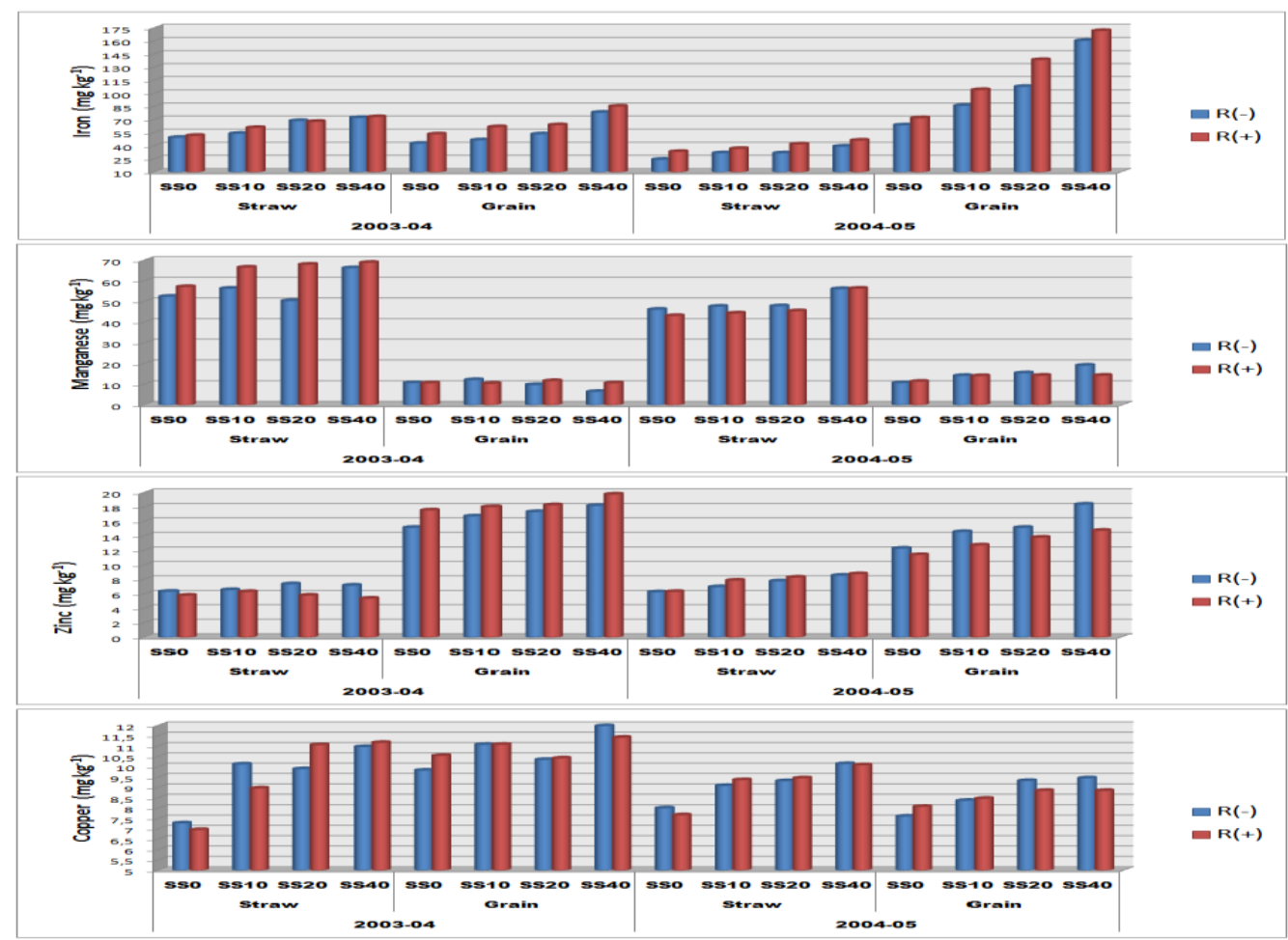

Figure 2. Effects of the applications on straw and grain micro element contents of lentil

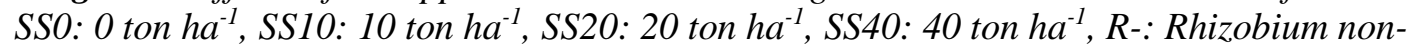
inoculation, $R+$ : Rhizobium non-inoculation

The highest value of straw content of $\mathrm{Fe}, \mathrm{Mn}, \mathrm{Zn}$ and $\mathrm{Cu}$ were reached at the application of 40-ton ha ${ }^{-1}$ of sewage sludge in both years and the lowest value level was detected at control parcels. The highest value was reached as $72.9 \mathrm{mg} \mathrm{kg}^{-1}$, $67.7 \mathrm{mg} \mathrm{kg}^{-1}, 6.57 \mathrm{mg} \mathrm{kg}^{-1}$ and $11.07 \mathrm{mg} \mathrm{kg}^{-1}$ respectively in first year; as $42.9 \mathrm{mg} \mathrm{kg}^{-1}$, $56.3 \mathrm{mg} \mathrm{kg}^{-1}, 8.66 \mathrm{mg} \mathrm{kg}^{-1}$ and $10.12 \mathrm{mg} \mathrm{kg}^{-1}$ respectively in second year. The alteration in content of straw micro element depending on inoculation was variable. Others were found to be insignificant while only iron was insignificant in the second year (Table 6, Figure 2).

Even though inoculation had insignificant effects on the grain micro element content of lentil in both years, except for Fe, it was seen that sewage sludge had very important effects on $\mathrm{Fe}, \mathrm{Zn}$ and $\mathrm{Cu}$ in both years, on $\mathrm{Mn}$ in the second year only (Table 7, Figure 2).

According to control, depending on applications of sewage sludge, Mn increased only in the second year, while $\mathrm{Fe}, \mathrm{Zn}$ and $\mathrm{Cu}$ increased highly in both years. The highest value was reached at the application of 40 -ton ha- of sewage sludge as $81.8 \mathrm{mg} \mathrm{kg}^{-1}$, $18.98 \mathrm{mg} \mathrm{kg}^{-1}$ and $11.70 \mathrm{mg} \mathrm{kg}^{-1}$ respectively in the first year and $166.2 \mathrm{mg} \mathrm{kg}^{-1}, 16.7$ $\mathrm{mg} \mathrm{kg}{ }^{-1}, 16.57 \mathrm{mg} \mathrm{kg}^{-1}$ and $9.16 \mathrm{mg} \mathrm{kg}^{-1}$ respectively in the second year (Table 7 , Figure 2).

\section{The effect of the applications to the straw and grain heavy metals content of lentil}

The results of variance analysis and the results of the averages of the effect of sewage sludge and Rhizobium applications on the straw and grain heavy metal contents of lentil are given in Table 8, 9, and Figure 3. 
Rhizobium application had a significant effect on the straw Co content of the lentil in the second year $(\mathrm{p}<0.05)$ and on the $\mathrm{Pb}$ content in both years $(\mathrm{p}<0.01)$. The effect of the sewage sludge application and interaction was significant only on $\mathrm{Pb}$ content in both years $(p<0.01)$. While the inoculation on grain heavy metal content of lentil had a significant effect on the content of $\mathrm{Pb}(\mathrm{p}<0.01)$ and $\mathrm{Cd}(\mathrm{p}<0.05)$ in the first year, the sewage sludge application had a significant effect on Co in the second year $(\mathrm{p}<0.05)$ and on $\mathrm{Pb}(\mathrm{p}<0.01 / \mathrm{p}<0.05)$ in both years. The effect of interference on grain heavy metal content was found to be insignificant (Table 8, 9).

As the doses of sewage sludge are increased, the content of straw heavy metal of lentil also increased. The highest value in $\mathrm{Co}, \mathrm{Pb}$, and $\mathrm{Cd}$ contents were reached at the application of 40-ton ha ${ }^{-1}$ of sewage sludge in both years as $2.714 \mathrm{mg} \mathrm{kg}^{-1} / 0.999 \mathrm{mg} \mathrm{kg}^{-}$ $1,0.618 \mathrm{mg} \mathrm{kg}^{-1} / 0.602 \mathrm{mg} \mathrm{kg}^{-1}, 0.201 \mathrm{mg} \mathrm{kg}^{-1} / 1.027 \mathrm{mg} \mathrm{kg}^{-1}$ respectively, and the lowest value was reached at control parcels. Inoculation only affected $\mathrm{Pb}$ content. Lead content decreased in the second year while it increased with inoculation in the first year (Table 8, Figure 3).

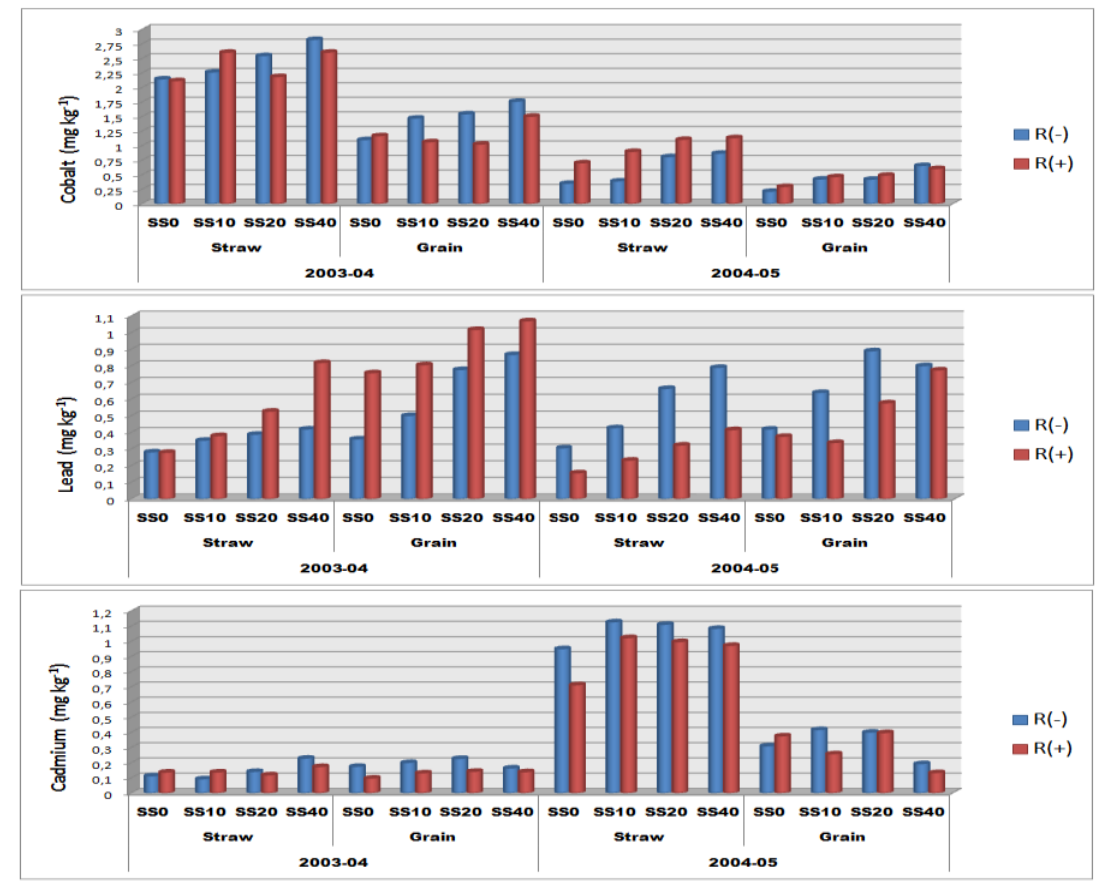

Figure 3. Effects of the applications on straw and grain micro element contents of lentil

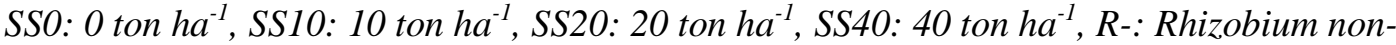
inoculation, $R+$ : Rhizobium non-inoculation

It was seen that sewage sludge had a statistically important effect on the grain heavy metal content of lentil with regards to $\mathrm{Co}$ in the second year and $\mathrm{Pb}$ in both years but its effect on Cd was insignificant (Table 9, Figure 3).

$\mathrm{Co}$ and $\mathrm{Pb}$ content increased significantly with the application of residual sewage sludge according to control in both years. The highest value was reached as $1.631 \mathrm{mg}$ $\mathrm{kg}^{-1}$ and $0.968 \mathrm{mg} \mathrm{kg}^{-1}$ respectively in the first year; as $0.628 \mathrm{mg} \mathrm{kg}^{-1}$ and $0.686 \mathrm{mg} \mathrm{kg}^{-1}$ respectively in the second year. Rhizobium inoculation decreased the taking of $\mathrm{Cd}$, while it increased the taking of $\mathrm{Pb}$ seed in the first year (Table 9, Figure 3). 
Çı̆ et al.: Determining the effects of sewage sludge and Rhizobium inoculation on nutrient and heavy metal content of lentil (Lens culinaris Medic.)

$$
-2711 \text { - }
$$

Table 8. Effects of Rhizobium and sewage sludge on heavy metal contents of lentil straw

\begin{tabular}{|c|c|c|c|c|c|c|}
\hline \multirow{2}{*}{ Treatments } & \multicolumn{2}{|c|}{ Cobalt (mg kg-1) } & \multicolumn{2}{|c|}{ Lead $\left(\mathrm{mg} \mathrm{kg}^{-1}\right)$} & \multicolumn{2}{|c|}{ Cadmium (mg kg-1) } \\
\hline & 2003-04 & 2004-05 & 2003-04 & 2004-05 & 2003-04 & 2004-05 \\
\hline \multicolumn{7}{|c|}{ Sewage Sludge (ton ha' $\left.{ }^{-1}\right)(\mathrm{SS})$} \\
\hline SS0 & $2.129 \mathrm{~b}^{*}$ & $0.524 \mathrm{~b}^{*}$ & $0.280 \mathrm{~d}^{* *}$ & $0.230 \mathrm{~d}^{* *}$ & $0.124 \mathrm{ab}^{*}$ & $0.831 \mathrm{~ns}$ \\
\hline SS10 & $2.432 \mathrm{ab}$ & $0.644 \mathrm{ab}$ & $0.365 \mathrm{c}$ & $0.329 \mathrm{c}$ & $0.115 \mathrm{~b}$ & 1.075 \\
\hline SS20 & $2.364 \mathrm{ab}$ & $0.956 \mathrm{a}$ & $0.456 \mathrm{~b}$ & $0.492 \mathrm{~b}$ & $0.130 \mathrm{ab}$ & 1.053 \\
\hline SS40 & $2.714 \mathrm{a}$ & $0.999 \mathrm{a}$ & $0.618 \mathrm{a}$ & $0.602 \mathrm{a}$ & $0.201 \mathrm{a}$ & 1.027 \\
\hline \multicolumn{7}{|l|}{ Rhizobium (R) } \\
\hline $\mathrm{R}(+)$ & $2.376 \mathrm{~ns}$ & $0.959 \mathrm{~ns}$ & $0.500 \mathrm{a}^{*}$ & $0.281 \mathrm{~b}^{* *}$ & $0.142 \mathrm{~ns}$ & $0.925 \mathrm{~ns}$ \\
\hline $\mathrm{R}(-)$ & 2.443 & 0.603 & $0.359 \mathrm{~b}$ & $0.546 \mathrm{a}$ & 0.143 & 1.068 \\
\hline \multicolumn{7}{|c|}{ Interactions (RxSS) } \\
\hline $\mathrm{R}(-) \mathrm{xSS} 0$ & $2.1437 \mathrm{~ns}$ & $0.3483 \mathrm{~ns}$ & $0.2808 \mathrm{~d}^{* *}$ & $0.3047 \mathrm{~d}^{* *}$ & $01117 \mathrm{~ns}$ & $0.9500 \mathrm{~ns}$ \\
\hline $\mathrm{R}(-) \mathrm{xSS} 10$ & 2.2620 & 0.3897 & $0.3508 \mathrm{~cd}$ & $0.4267 \mathrm{c}$ & 0.0925 & 1.1267 \\
\hline $\mathrm{R}(-) \mathrm{xSS} 20$ & 2.5443 & 0.8067 & $0.3867 \mathrm{~cd}$ & $0.6623 \mathrm{~b}$ & 0.1408 & 1.1100 \\
\hline $\mathrm{R}(-) \mathrm{xSS} 40$ & 2.8227 & 0.8657 & $0.4183 \mathrm{c}$ & $0.7889 \mathrm{a}$ & 0.2283 & 1.0833 \\
\hline $\mathrm{R}(+) \times \mathrm{SS} 0$ & 2.1133 & 0.7007 & $0.2783 \mathrm{~d}$ & $0.1551 \mathrm{e}$ & 0.1367 & 0.7117 \\
\hline $\mathrm{R}(+) \mathrm{xSS} 10$ & 2.6027 & 0.8973 & $0.3787 \mathrm{~cd}$ & $0.2313 \mathrm{de}$ & 0.1375 & 1.0225 \\
\hline $\mathrm{R}(+) \mathrm{xSS} 20$ & 2.1843 & 1.1043 & $0.5258 \mathrm{~b}$ & $0.3218 \mathrm{~d}$ & 0.1185 & 0.9967 \\
\hline $\mathrm{R}(+) \mathrm{xSS} 40$ & 2.6043 & 1.1323 & $0.8183 \mathrm{a}$ & $0.4146 \mathrm{c}$ & 0.1733 & 0.9717 \\
\hline
\end{tabular}

ns: not significant; *: Significant at $\mathrm{P}<0.05$ level, **: Significant at $\mathrm{P}<0.01$ level, \#: Values followed by the different letters are significantly different, SS0: 0 ton ha-1, SS10: 10 ton ha ${ }^{-1}$, SS20: 20 ton ha-1, SS40: 40 ton $\mathrm{ha}^{-1}$, R(-): Rhizobium non-inoculation, $\mathrm{R}(+)$ : Rhizobium inoculation

Table 9. Effects of Rhizobium and sewage sludge on heavy metal contents of lentil grain

\begin{tabular}{|c|c|c|c|c|c|c|}
\hline \multirow{2}{*}{ Treatments } & \multicolumn{2}{|c|}{ Cobalt (mg kg-1) } & \multicolumn{2}{|c|}{ Lead $\left(\mathrm{mg} \mathrm{kg}^{-1}\right)$} & \multicolumn{2}{|c|}{ Cadmium (mg kg-1) } \\
\hline & 2003-04 & 2004-05 & 2003-04 & 2004-05 & 2003-04 & 2004-05 \\
\hline \multicolumn{7}{|c|}{ Sewage Sludge (ton ha' $\left.{ }^{-1}\right)(\mathrm{SS})$} \\
\hline SS0 & $1.133 \mathrm{~b} \mathrm{~ns}$ & $0.253 \mathrm{c}^{* *}$ & $0.558 \mathrm{~b}^{* *}$ & $0.393 \mathrm{c}^{*}$ & $0.136 \mathrm{~ns}$ & $0.342 \mathrm{~ns}$ \\
\hline SS10 & $1.267 \mathrm{ab}$ & $0.443 \mathrm{~b}$ & $0.652 \mathrm{~b}$ & $0.488 \mathrm{bc}$ & 0.166 & 0.275 \\
\hline SS20 & $1.282 \mathrm{ab}$ & $0.454 \mathrm{~b}$ & $0.897 \mathrm{a}$ & $0.732 \mathrm{ab}$ & 0.184 & 0.398 \\
\hline SS40 & $1.631 \mathrm{a}$ & $0.628 \mathrm{a}$ & $0.968 \mathrm{a}$ & $0.787 \mathrm{a}$ & 0.151 & 0.225 \\
\hline \multicolumn{7}{|l|}{ Rhizobium (R) } \\
\hline $\mathrm{R}(+)$ & $1.188 \mathrm{~ns}$ & $0.462 \mathrm{~ns}$ & $0.912 \mathrm{a}^{*}$ & $0.515 \mathrm{~ns}$ & $0.128 b^{*}$ & $0.291 \mathrm{~ns}$ \\
\hline $\mathrm{R}(-)$ & 1.468 & 0.427 & $0.625 \mathrm{~b}$ & 0.686 & $0.191 \mathrm{a}$ & 0.330 \\
\hline \multicolumn{7}{|c|}{ Interactions (RxSS) } \\
\hline $\mathrm{R}(-) \mathrm{xSS} 0$ & $1.0990 \mathrm{~ns}$ & $0.2113 \mathrm{~ns}$ & $0.3590 \mathrm{~ns}$ & $0.4183 \mathrm{~ns}$ & $0.174 \mathrm{~ns}$ & $0.309 \mathrm{~ns}$ \\
\hline $\mathrm{R}(-) \mathrm{xSS} 10$ & 1.4693 & 0.4223 & 0.4992 & 0.6383 & 0.200 & 0.417 \\
\hline $\mathrm{R}(-) \mathrm{xSS} 20$ & 1.5430 & 0.4190 & 0.7761 & 0.8888 & 0.227 & 0.400 \\
\hline $\mathrm{R}(-) \mathrm{xSS} 40$ & 1.7603 & 0.6547 & 0.8667 & 0.7992 & 0.164 & 0.195 \\
\hline $\mathrm{R}(+) \mathrm{xSS} 0$ & 1.1670 & 0.2937 & 0.7567 & 0.3743 & 0.098 & 0.375 \\
\hline $\mathrm{R}(+) \times S S 10$ & 1.0637 & 0.4627 & 0.8050 & 0.3373 & 0.132 & 0.258 \\
\hline $\mathrm{R}(+) \mathrm{xSS} 20$ & 1.0217 & 0.4880 & 1.0174 & 0.5758 & 0.142 & 0.397 \\
\hline $\mathrm{R}(+) \times S S 40$ & 1.5010 & 0.6017 & 1.0690 & 0.7738 & 0.139 & 0.133 \\
\hline
\end{tabular}

ns: not significant; *: Significant at $\mathrm{P}<0.05$ level, **: Significant at $\mathrm{P}<0.01$ level, \#: Values followed by the different letters are significantly different, SS0: 0 ton ha $\mathrm{ha}^{-1}$ SS10: 10 ton ha ${ }^{-1}$, SS20: 20 ton ha-1, SS40: 40 ton $\mathrm{ha}^{-1}, \mathrm{R}(-)$ : Rhizobium non-inoculation, $\mathrm{R}(+)$ : Rhizobium inoculation 


\section{Discussion}

In our study, it was determined that the increasing applications of sewage sludge increase the amount of lentils' straw and grain macro, micro and heavy metal contents in both years. The highest values were reached in 40-ton sewage sludge ha- ${ }^{-1}$ applied parcels. Increases in $\mathrm{N}, \mathrm{P}, \mathrm{K}, \mathrm{Ca}, \mathrm{Mg}, \mathrm{Fe}, \mathrm{Mn}, \mathrm{Cu}, \mathrm{Co}$, and $\mathrm{Pb}$ contents of the lentil straw in the first year were respectively $17.9 \%, 19.7 \%, 16.8 \%, 13.4 \%, 5.4 \%, 44.1 \%$, $23.5 \%, 55.5 \%, 27.5 \%, 120.7$ and in the second year they $12.7 \%, 47.7 \%, 37.8 \%, 19.1 \%$, $3.0 \%, 48.4 \%, 25.9 \%, 29.1 \%, 90.7 \%, 161.7 \%$, respectively. The straw zinc content increased by $37.7 \%$ in the second year and the cadmium content increased by $62.1 \%$ in the first year. The first and second year increases in the grain nutrient and heavy metal contents were respectively $\mathrm{N} ; 6.7 \%-13.3 \%, \mathrm{P} ; 16.5 \%-9.8 \%, \mathrm{~K} ; 36.5 \%-44.6 \%$, Ca; 52.7\%-16.1\%, Mg; 75.2\%-24.6\%, Fe; 70.1\%-144.8\%, Mn; 51.8\%, Zn; 15.9\%-39.8\%, $\mathrm{Cu} ; 14.9 \%-16.7 \%, \mathrm{Co} ; 43.9 \%-148.2 \%$ and $\mathrm{Pb} ; 73.5 \%-100.3 \%$. Even though there was a decrease in the grain Cd content, this was found to be statistically insignificant (Table 4, Table 5, Figure 1).

In similar studies, it has been reported that plants' nutrient and heavy metal contents go up as a result of increasing sewage sludge applications (Sönmez and Bozkurt, 2005; Tüfenkçi et al., 2006b; Yürük and Bozkurt, 2006; Singh and Agrawal, 2010). This is probably because of the changes in the nutrient element composition of soils with sewage sludge. Indeed, Antolin et al. (2005) reported in their study that with the addition of long-term sewage sludge, there is a decrease in the $\mathrm{pH}$ of the soil and increase in the total organic carbon and DTPA extractable heavy metal content. In other relevant studies, it was reported that there was an improvement in the physical and chemical properties of the soil with the addition of sewage sludge. The amount of product and the nutrient element contents increased too (Barzegar et al., 2002; Speir et al., 2003; Sönmez and Bozkurt, 2005; Tüfenkçi et al., 2006b). With a high rate of sewage sludge addition, the cation exchange capacity (CEC) of soils increases (Soon, 1981) and the bioavailability of heavy metals become limited (Kladivko and Nelson, 1979; Kim and Kim, 1999).

With Rhizobium inoculation; the phosphorus, potassium, calcium and magnesium contents of straw and grain nitrogen have increased within the years. These increases were $21.3 \%-9.4 \%, 44.1 \%-1.9 \%, 8.9 \%-1.8 \%-10.5 \%-11.9 \%$ and $2.6 \%-0.3 \%$ respectively in lentil straw and $2.9 \%-7.6 \%, 6.2 \%-2.0 \%, 10.3 \%-2.6 \%, 20.2 \%-3.4 \%$ and $8.5 \%-1.5 \%$ respectively in lentil grain (Table 4, Table 5, Figure 1). It is reported by some researchers that Rhizobium inoculation provides significant increases, especially in the nitrogen content, as well as in plant growth (Marschner, 1995; Al-Karaki, 1999; Kacar and Katkat, 1999; Soumaya et al., 2016; Tüfenkçi et al., 2006a). The physical and chemical properties of soils have a significant effect on microorganism activities (Ham, 1980; Lowendorf, 1980; Haktanır and Arcak, 1997). In addition to being a good source of organic fertilizers with high organic matter and nutrients, sewage sludge should be used with caution due to the high amount of heavy metals they contain (Fernandes, 2005; Bozkurt et al., 2006; Carbonell et al., 2009; Fernandez et al., 2009). Applied sewage sludge affects the physical, chemical and biological properties of soil and therefore affects the microorganism activities. This is also seen in the results reported by some researchers (Chaudri et al., 2008; El-Azhari et al., 2012; Charlton et al., 2016). As a matter of fact, Mattanaa et al. (2014) reported that the effects of sewage sludge on soil microorganisms are different according to the methods applied to the sludge before. 
Antolin et al. (2010) stated that the addition of sewage sludge has no significant effect on nodulation.

The effect of inoculation on grain and straw micro element content compared to noninoculated plants is evident in iron values. Manganese and zinc were detected only in the grain in the second year. Iron increases in the first and second year straw and grain are respectively $3.8 \%-24.5 \%$ and $19.5 \%-16.4 \%$. In the second year, $10.4 \%$ increase in grain manganese and $14.6 \%$ decrease in zinc were determined. It was seen that inoculation in copper did not make a significant difference (Table 6, Table 7, Figure 2). Zribi et al. (2012) reported that Medicago sativa-sinorhizobium symbiosis could be used for phytoremediation in medium polluted areas with $\mathrm{Cd}, \mathrm{Cu}, \mathrm{Pb}$ and $\mathrm{Zn}$.

The significant effect of Rhizobium inoculation on the heavy metal content was determined as an increase in the cobalt content of the lentil straw in the second year and lead in both years by $59.0 \%, 39.3 \%$ and $94.3 \%$, respectively. The effect of inoculation on the grain heavy metal content of lentil is designated in lead and cadmium contents. Despite the increase in lead content in both years, it was seen that only the first year was important. It was seen that there was an increase of $45.9 \%$ compared to non-inoculated plants. The cadmium content was decreased with inoculation by $49.2 \%$ in the first year and $13.4 \%$ in the second year. The decrease with inoculation in the cobalt content during the first year was $23.6 \%$, but this decrease was deemed insignificant (Table 8, Table 9, Figure 3). Akhtar et al. (2018) reported that Rhizobium inoculation has a positive effect on metal contaminated areas. Ghnaya et al. (2018) reported that Rhizobium inoculation in cadmium-contaminated environments increased the root cd content of Medicago sativa L. and increased the transport to the surface of the plant.

\section{Conclusion}

Rhizobium inoculation is particularly recommended in legumes. Due to rapid population increase and technological developments, the amount of treatment sludge is increased. It is currently being investigated for the disposal of sewage sludge, which is an important problem for use in agricultural areas. In this study, the efficiency of treatment sludge use and Rhizobium inoculation in legumes was investigated. As a result, Rhizobium inoculation has been found to have a positive effect on both the lentil and the nutrient element content.

In increasing applications of sewage sludge, Rhizobium inoculation has been shown to have a more pronounced effect on the straw element content of lentils, especially in the first year trials than in Rhizobium non-inoculation.

The most important disadvantage of the use of sewage sludge is the risk of heavy metal contents of soil and plant. In this study, Rhizobium inoculation has been shown to have a negative effect on the absorption of heavy metals against increasing sludge applications. The chemical composition of the treatment sludge to be used in such studies should be considered and accordingly the application dose should be adjusted.

As a result, we have determined that the use of sewage sludge is not a risk for heavy metal in terms of both soil and plant and it can be used with Rhizobium inoculation. 


\section{REFERENCES}

[1] Akhtar, N., Hussain, A., Riaz, A., Aftab, M. (2018): Biremediation of heavy metal stress by Rhizobium chickpea symbiosis. - Journal of Agricultural Research 56(1): 27-34.

[2] Al-Karaki, G. N. (1999): Rhizobium and phosphorus influence on lentil seed protein and lipid. - Journal of Plant Nutrition 22(2): 351-358.

[3] Anonymous. (2003): Regulation on control of soil pollution. http://www.resmigazete.gov.tr/eskiler/2005/05/20050531-6.htm.

[4] Antolin, M. C., Pascual, I., Garcia, C., Polo, A., Sanchez-Diaz, M. M. (2005): Growth, yield and solute content of barley in soils treated with sewage sludge under semiarid Mediterranean conditions. - Field Crops Research 94: 224-237.

[5] Antolin, M. C., Fiasconaro, M. L., Sanchez-Diaz, M. (2010): Relationship between photosynthetic capacity, nitrogen assimilation and nodule metabolism in alfalfa (Medicago sativa) grown with sewage sludge. - Journal of Hazardous Materials 182: 210-216.

[6] Athar, R., Ahmad, M. (2002): Heavy metal Toxicity: Effect on plant growth and metal uptake by wheat, and on free living azotobacter. - Water, Air, and Soil Pollution 138: 165-180.

[7] Barzegar, A. R., Yousefi, A., Daryashenas, A. (2002): The effect of addition of different amounts and types of organic materials on soil physical properties and yield of wheat. Plant and Soil 247: 295-301.

[8] Bouyoucous, G. D. (1951): A recalibration of the hydrometer method for making mechanical analysis of the soil. - Agronomy Journal 43: 434-438.

[9] Bozkurt, M. A., Akdeniz, H., Keskin, B., Yilmaz, I. H. (2006): Possibilities of using sewage sludge as nitrogen fertilizer for maize. - Acta Agriculturae Scandinavica, Section B - Soil \& Plant Science 56: 143-149.

[10] Brynhildsen, L., Rosswall, T. (1997): Effects of metals on the microbial mineralization of organic acids. - Water, Air, and Soil Pollution 94: 45-57.

[11] Carbonell, G., Pro, J., Gomez, N., Babin, M. M., Fernandez, C., Alonso, E., Tarazona, J. V. (2009): Sewage sludge applied to agricultural soil: Effects on representative soil organisms. - Ecotoxicology and Environmental Safety 72: 1309-1319.

[12] Charlton, A., Sakrabani, R., Tyrrel, S. F., Rivas, C. M., McGrath, S. P., Crooks, B., Cooper, P., Campbell, C. D. (2016): Long-term impact of sewage sludge application on soil microbial biomass: An evaluation using meta-analysis. - Environmental Pollution 219: 1021-1035.

[13] Chaudri, A. M., McGrath, S. P., Giller, K. E., Rietz, E., Sauerbeck, D. R. (1993): Enumeration of indigenous Rhizobium leguminosarum biovar trifolii in soils previously treated with metal-contaminated sewage sludge. - Soil Biology and Biochemistry 25: 301-309.

[14] Chaudri, A. M., Allain, C. M. G., Barbosa-Jefferson, V. L., Nicholson, F. A., Chambers, B. J., McGrath, S. P. (2000): A study of the impacts of $\mathrm{Zn}$ and $\mathrm{Cu}$ on two rhizobial species in soils of a long-term field experiment. - Plant and Soil 221: 167-179.

[15] Chaudri, A., McGrath, S., Gibbs, P., Chambers, B., Carlton-Smith, C., Bacon, J., Campbell, C., Aitken, M. (2008): Population size of indigenous Rhizobium leguminosarum biovar trifolii in long-term field experiments with sewage sludge cake, metal-amended liquid sludge or metal salts: Effects of zinc, copper and cadmium. - Soil Biology and Biochemistry 40: 1670-1680.

[16] Düzgüneş, O., Kesici, T., Kavuncu, O., Gürbüz, F. (1987): Research and Trial Methods. Ankara University Agricultural Faculty Publication No: 1021, Practice Guide: 295, 381.

[17] El-Azhari, N., Lainé, S., Sappin-Didier, V., Beguet, J., Rouard, N., Philippot, L., MartinLaurent, F. (2012): Long-term impact of 19 years' farmyard manure or sewage sludge application on the structure, diversity and density of the protocatechuate-degrading bacterial community. - Agriculture, Ecosystems and Environment 158: 72-82. 
[18] Fernandes, S. A. P., Bettiol, W., Cerri, C. C. (2005): Effect of sewage sludge on microbial biomass, basal respiration, metabolic quotient and soil enzymatic activity. Applied Soil Ecology 30: 65-77.

[19] Fernandez, J. M., Plaza, C., Garcia-Gil, J. C., Polo, A. (2009): Biochemical properties and barley yield in a semiarid Mediterranean soil amended with two kinds of sewage sludge. - Applied Soil Ecology 42: 18-24.

[20] Ghnaya, T., Mnassri, M., Ghabriche, R., Wali, M., Poschenrieder, C., Lutts, S., Abdelly, C. (2015): Nodulation by Sinorhizobium meliloti originated from a mining soil alleviates Cd toxicity and increases Cd-phytoextraction in Medicago sativa L. - Frontiers in Plant Sciences 6: 1-10.

[21] Glick, B. R. (2004): Changes in plant growth and development by rhizosphere bacteria that modify plant ethylene levels. - International Society for Horticultural Science 631: 265-273.

[22] Haferburg, G., Kothe, E. (2007): Microbes and metals: Interactions in the environment. Journal of Basic Microbiology 47: 453-467.

[23] Haktanır, K., Arcak, S. (1997): Soil Biology (Introduction to Soil Ecosystem). - Ankara University, Faculty of Agriculture. Faculty of Agriculture Publications No: 1486, Textbook: 447.

[24] Ham, G. E. (1980): Inoculation of legumes with Rhizobium in competition with naturalized strains. - In: Newton, W. E., Orme-Johnson, W. H. (eds.) Nitrogen fixation, vol. II. Univ. Park Press, Baltimore, Md. p: 131-138.

[25] Hizalan, E., Ünal, E. (1966): Important analysis in soils. - Ankara University, Faculty of Agriculture. Publication No: 278.

[26] Jackson, M. (1958): Soil Chemical Analysis. - Prentice Hall, Inc. New Jersey, USA.

[27] Kacar, B. (1994): Chemical analysis of plant and soil: III. Soil analysis, Ankara University, Faculty of Agriculture Ed. Research and Development Foundation No: 3, Ankara.

[28] Kacar, B., Katkat, V. (1999): Fertilizers and fertilization techniques. - Uludağ University Strengthening Foundation Publication No: 144. Vipaş Publication No: 20. Bursa.

[29] Kacar, B., İnal, A. (2008): Plant analysis. - Nobel Publication No: 1241, Science:63.

[30] Kim, K. H., Kim, S. H. (1999): Heavy metal pollution of agricultural soils in central regions of Korea. - Water Air and Soil Pollution 111: 109-122.

[31] Kladivko, E. J., Nelson, D. W. (1979): Changes in soil properties from application of anaerobic sludge. - Journal of the Water Pollution Control Federation 51: 325-32.

[32] Lindsay, W. V., Norvell, W. A. (1978): Development of a DTPA soil test for Zinc, Iron, Manganese and Copper. - Soil Science Society of American Journal 42: 421-428.

[33] Logan, T. J., Chaney, R. L. (1983): Metals. - In: Page, A. L., Gleason, T. L., Smith, J. E., Iskander, I. K., Sommers, L. E. (eds.) Utilization of Municipal Wastewater and Sludge on Land. University of California, Riverside 235-326.

[34] Lovell, B., Toombs, M., Blackie, M., Schleihauf, J. (1995): Land Application of Sewage Biosolids for Crop Production. - Ministry of Agriculture, Food and Rural Affairs. http://www.gov.on.ca:80/OMAFRA/english/environment/facts/95-069.htm.

[35] Lowendorf, H. S. (1980): Factors affecting survival of Rhizobium soils. - In: Alexander, M. (ed.). Advances in Microbial Ecology. Plenum Publishing Corp., New York. pp. 87123.

[36] Marschner, H. (1995): Mineral Nutrition of Higher Plants. Second edition. - Academic press limited 24-28 oval road, London, ISBN; 0-12-473543-6.

[37] Mattanaa, E. B., Petrovǐcováb, L., Landic, A., Gelsominob, P., Cortésd, O., Ortiza, E., Renella, G. (2014): Sewage sludge processing determines its impact on soil microbial community structure and function. - Applied Soil Ecology 75: 150-161.

[38] Mueller, J. G., Chapman, P. J., Pritchard, P. H. (1989): Creosote contaminated sites. Environmental Science and Technology 23: 1197-1201. 
[39] Nellessen, J. E., Fletcher, J. S. (1993): Assessment of published literature on the uptake, accumulation, and translocation of heavy metals by vascular plants. - Chemosphere 27(9): 1669-1680.

[40] Olsen, S. R., Cole, V., Watanabe, F. S., Dean, L. A. (1954): Estimations of Available Phosphorus in Soils by Extractions with Sodium Bicarbonate. - United States Department of Agriculture 939-941.

[41] Richards, L. A. (1954): Diagnosis and Improvement of Saline and Alkaline Soils. Handbook 60. United States Department of Agriculture.

[42] Singh, R. P., Agrawal, M. (2010): Effect of different sewage sludge applications on growth and yield of Vigna radiata L. field crop: Metal uptake by plant. - Ecological Engineering 36: 969-972.

[43] Smith, S. R. (1996): Agricultural recycling of sewage sludge and the Environment. Agricultural recycling of sewage sludge and the environment 1995 pp.xi +382 pp. ref.71 pp. of - CAB International, Wallingford.

[44] Somesagaran, P., Hoben, H. J. (1994): Handbook for Rhizobia: Methods in legumeRhizobium technology. - Springer-Verlag, New York, N.Y.

[45] Soon, Y. K. (1981): Solubility and sorption of cadmium in soils amended with sewage sludge. - Journal of Soil Science.32: 85-95.

[46] Soumaya, T. H., Sana, D. F., Faysal, B. J., Imran, H. (2016): Effect of Rhizobium inoculation on growth and nutrient uptake of sulla (Hedysarum coronarium L.) grown in calcareous soil of northern Tunisia. - Romanian Biotechnological Letters 21(4): 1163211639.

[47] Sönmez, F. (2003): Effects of sewage sludge and humic acids treatments on the yield, nutrient and heavy metal contents of lettuce. - Yuzuncu Y1l University, Master's thesis, Van.

[48] Sönmez, F., Bozkurt, M. A (2005): Lettuce grown on calcareous soils benefit from sewage sludge. - Acta Agriculturae Scandinavica, Section B - Soil \& Plant Science 56(1): 17-24.

[49] Speir, T. W., Van Schaik, A. P., Lloyd-Jones, A. R., Kettles, H. A. (2003): Temporal response of soil biochemical properties in a pastoral soil after cultivation following high application rates of undigested sewage sludge. - Biology and Fertility of Soils 38: 377385.

[50] Sterritt, R. M., Lester, J. N. (1980): Interactions of heavy metals with bacteria. - Science of the Total Environment 14: 5-17.

[51] Thomas, G. W., 1982, "Exchangeable cations. methods of soil analysis, Part 2, Chemical and microbiological properties", Second Edition. A.L. Page (editor). Agronomy, No. 9, Part 2, American Society of Agronomy, Soil Science Society of America, Madison, Wl: 159-165.

[52] TSMS. (2006): Reports of Turkish State Meteorological Service. - Ankara, Turkey.

[53] Tüfenkci, Ş., Türkmen, Ö., Sönmez, F., Erdinç, Ç., Sensoy, S. (2006a): Effects of humic acid doses and application times on the plant growth, nutrient and heavy metal contents of lettuce grown on sewage sludge-applied soils. - Fresenius Environmental Bulletin 15(4): 295-300.

[54] Tüfenkci, Ş., Erman, M., Sönmez, F. (2006b): Effects of phosphorus and nitrogen applications and Rhizobium inoculation on the yield and nutrient uptake of sainfoin (Onobrychis viciifolia L.) under irrigated conditions in Turkey. - New Zealand Journal of Agricultural Research. 49: 101-105.

[55] Van Assche, F., Clijsters, H. (1990): Effects of metals on enzyme activity in plants. Plant, Cell and Environment 13: 195-206.

[56] Vincent, V. M. (1970): A Manual for the Practical Study of Root-Nodule Bacteria pp.164 pp. - IBP Handbook no: 15, Oxford and Edinburgh, Blackwell Scientific Publications. 
[57] Walkey, A. (1947): A critical examination of a rapid method for determining organic carbon in soils: Effect of variations in digestion conditions and inorganic soil constituents. - Soil Science 63: 251-263.

[58] Xian, X. (1989): Response of kidney bean to concentration of chemical form of cadmium, zinc and lead in polluted soils. - Environmental Pollution 57(2): 127-137.

[59] Yürük, A., Bozkurt, M. A. (2006): Heavy metal accumulation in different organs of plants grown under high sewage sludge doses. - Fresenius Environmental Bulletin 15(2): 107-112.

[60] Zribi, K., Djébali, N., Mrabet, M., Khayat, N., Smaoui, A., Mlayah, A., Aouani, M. E. (2012): Physiological responses to cadmium, copper, lead, and zinc of Sinorhizobium sp. strains nodulating Medicago sativa grown in Tunisian mining soils. - Annals of Microbiology 62(3): 1181-1188. 